\title{
Why do people attempt suicide? A mixed-methods research from south India
}

\author{
Purushothaman $\mathrm{P}^{1 *}$, Premarajan $\mathrm{KC}^{2}$, Ramakrishnan $\mathrm{J}^{3}$, Thyagarajan $\mathrm{S}^{4}$, Lakshminarayanan $\mathrm{S}^{5}$, \\ Debasish $\mathrm{L}^{6}$
}

\section{*Corresponding author:}

Dr. Punithakumary P, MBBS, MD, Assistant Professor.

Email: puniothakumary.p@gmail.com, $\underline{\text { ORCID }}$

${ }^{1}$ Department of Community Medicine, PSG Institute of Medical Science and Research, Coimbatore, Tamil Nadu, India,

${ }^{2}$ Department of Preventive and Social Medicine, JIPMER, Pondicherry, India

${ }^{3}$ Department of Preventive and Social Medicine, JIPMER, Puducherry, India

${ }^{4}$ Department of Community Medicine, Stanley Medical College, Chennai, India

${ }^{5}$ Department of Preventive and Social Medicine, JIPMER, Puducherry

${ }^{6}$ Department of Community Medicine, IGMC\&RI, Pondicherry, India

Information about the article:

Received: Jan. 17, 2019

Accepted: Feb. 20, 2019

Published online: Dec. 27, 2019

Publisher

Nepal Health Research Society, Bahundhara -6, Gokarnesowor Municipality, Kathmandu, Nepal eISSN 2382-5545, ISSN 2676-1343 (Print)

(C) The Author(s). 2019

Content licensing: CC BY 4.0

\section{ABSTRACT}

\section{Background}

Suicide is a major public health problem and a leading cause of death worldwide. In 2009, the suicide rate in Tamil Nadu and in Pondicherry was 21.5 per lakh and 47.2 per lakh population respectively. This is more than four times the rate as compared to the national level. Suicidal attempts are 20 times higher than the completed suicides. Mixed-method design gives better understanding of the complexity of the path from suicide ideation to suicidal attempt.

\section{Materials and methods}

A (QUAN - QUAL) Sequential Explanatory design was used. Among 200 patients admitted for attempted suicide in JIPMER and Indira Gandhi Government Hospital and Post Graduate Institute Pondicherry were assessed for the reasons for attempting suicide using a semi-structured questionnaire. For a subsample of 40(20\%) In-depth interview was done to explore and understand the reasons and the undermined situation associated with attempted suicide at their residence.

\section{Results}

Among the study subjects $(n=200)$, more than half were in the age group of 20-29 years, mean ( \pm standard deviation) age of suicide attempt was $26 \pm 9.1$ years. Commonest reason (precipitating factor) for attempting suicide was verbal abuse, most often by parents (31.9\%). Other precipitating factors were physical abuse, illness, marital conflict, family related problem, etc. On IDI, it was found that there were several, background factors (like chronic ill health; loss of family member, delayed marriage, alcoholism, and heavy debt), aggravating factors (like verbal or physical abuse, neighborhood influence, guilt), and protective factor (like religious affiliation, motherhood feel, caring and loving parents). A conceptual diagram was generated depicting the imbalance between the protective and aggravating factors acting on the background factors before the execution of a suicide attempt. In the presence of background factor, the suicidal ideation progressed to suicidal intention and ended in attempt. Not all suicide attempts were preceded with suicidal intention or ideation. Some attempts occurred as an impulsive thought or to threaten the family member.

\section{Conclusion}

There is lot of scope to reduce the suicidal attempts in our country. Opportunistic screening should be done to identify any psycho-social issues among patients attending OPD. Strong social support and enabling environment should be provided for counseling individuals with suicidal ideation and intentions.

\section{Keywords}

Mixed- method approach, qualitative research, south India, suicidal ideations, suicide 